OPEN ACCESS

Edited by:

Yulong Wu,

Tsinghua University, China

Reviewed by: Kannan Srinivasan, Central Salt and Marine Chemicals Research Institute (CSIR), India Huijuan Wei,

Zhengzhou University, China

${ }^{*}$ Correspondence:

Xin Jin

jamesjinxin@upc.edu.cn

Specialty section: This article was submitted to Green and Sustainable Chemistry, a section of the journal

Frontiers in Chemistry

Received: 01 November 2019 Accepted: 28 February 2020

Published: 31 March 2020

Citation:

Yan W, Zhang G, Wang J, Liu M, Sun $Y$, Zhou Z, Zhang W, Zhang $S$, Xu X, Shen J and Jin X (2020) Recent

Progress in Adipic Acid Synthesis

Over Heterogeneous Catalysts.

Front. Chem. 8:185.

doi: 10.3389/fchem.2020.00185

\section{Recent Progress in Adipic Acid Synthesis Over Heterogeneous Catalysts}

\author{
Wenjuan Yan ${ }^{1}$, Guangyu Zhang ${ }^{1}$, Jinyao Wang ${ }^{1}$, Mengyuan Liu ${ }^{1}$, Yu Sun ${ }^{1}$, Ziqi Zhou ${ }^{1}$, \\ Wenxiang Zhang ${ }^{1}$, Shuxia Zhang ${ }^{1}$, Xiaoqiang $\mathrm{Xu}^{2}$, Jian Shen ${ }^{3}$ and Xin $\mathrm{Jin}^{1 *}$ \\ 1 State Key Laboratory of Heavy Oil Processing, Center for Chemical Engineering Experimental Teaching, China University of \\ Petroleum, Qingdao, China, ${ }^{2}$ Oil Production Group\#2, Huabei Oil Field Company at PetroChina, Langfang, China, ${ }^{3}$ College \\ of Environment and Resources, Xiangtan University, Xiangtan, China
}

Adipic acid is one of the most important feedstocks for producing resins, nylons, lubricants, plasticizers. Current industrial petrochemical process, producing adipic acid from KA oil, catalyzed by nitric acid, has a serious pollution to the environment, due to the formation of waste nitrous oxide. Hence, developing cleaner methods to produce adipic acid has attracted much attention of both industry and academia. This mini-review article discussed advances on adipic acid synthesis from bio-renewable feedstocks, as well as most recent progress on cleaner technology from fossil fuels over novel catalytic materials. This work on recent advances in green adipic acid production will provide insights and guidance to further study of various other industrial processes for producing nylon precursors.

Keywords: nanostructured catalyst, glucose, glucaric acid, adipic acid, cyclohexanone, polyoxometalates

\section{INTRODUCTION}

Adipic acid (AA) has immense practical use in industrial for the production of nylon-66, nylon-6, lubricant and plasticizer (Feng et al., 2019; Perkel and Voronina, 2019; Pisk et al., 2019; Yang B. et al., 2019; Yang J. et al., 2019). In current industrial processes, AA is synthesized mainly by oxidation of KA oil using 50-60\% nitric acid as oxidant and copper/ammonium metavanadate as the catalyst (Van de Vyver and Roman-Leshkov, 2013; Deng et al., 2016; Rahman et al., 2016). However, this process emits nitrous oxide which can cause ozone depletion, acid rain, and global warming. Furthermore, the applicability of the phase-transfer catalyst in industrial scale is expensive. Obviously, we need to develop more sustainable AA manufacturing process which can avoid the use of toxic reagents and tedious products separation (Dugal et al., 2000; Cheng et al., 2007; Fujitani et al., 2009; Jin et al., 2011; Indulkar et al., 2012; Lu et al., 2012; Vafaeezadeh et al., 2012).

Cyclohexane, cyclohexanol, cyclohexanone can be oxidized to produce AA without formation of any greenhouse gases (Sato et al., 1998; Chatterjee et al., 2018; Luo et al., 2018; Mazzi et al., 2018; Mouheb et al., 2018; Wang et al., 2018). Oxygen, air, hydrogen peroxide $\left(\mathrm{H}_{2} \mathrm{O}_{2}\right)$ are regarded as clean oxidant since they give water as the only byproduct. It is essential to use separable and reusable inexpensive catalysts for development of sustainable protocols (Baig and Varma, 2012). Various of solid supported catalysts, such as metal oxides, (Hereijgers and Weckhuysen, 2010; Makgwane and Ray, 2014) hollow structure silicates, (Dai et al., 2016; Xia et al., 2018) carbon nanotubes (CNTs), (Machado et al., 2014; Yang et al., 2016) and polyoxometalates (POMs), (Luo et al., 2018) 


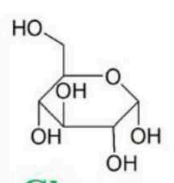

Glucose<smiles>C1CCCCC1</smiles>

Cyclohexane<smiles>OC1CCCCC1</smiles>

Cyclohexanol<smiles>O=C1CCC2CCC1C2</smiles>

Cyclohexanone
$\mathrm{Au}-\mathrm{Pd} / \mathrm{ZrO}_{2}$ Au-GOS Dawson POMs

Mn-HTS

$\mathrm{Fe} @ \mathrm{CNT} \quad \mathrm{Cu} / \mathrm{WQ}_{3}$

Ru/HAP Fe-HTS Anderson POMs

V-HTS TS-1

TIPQ-1 $\quad \mathrm{Al}_{2} \mathrm{O}_{3} @ \mathrm{Fe}_{2} \mathrm{O}_{3}$

Keggin PQMS

Au-Pt/C

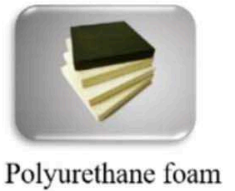

Polyurethane foam

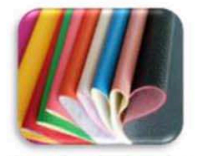

Synthetic leather<smiles>O=C(O)CCCCC(=O)O</smiles>

Adipic acid

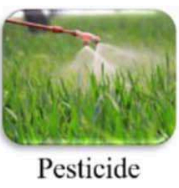

Nylon 6, Nylon 66

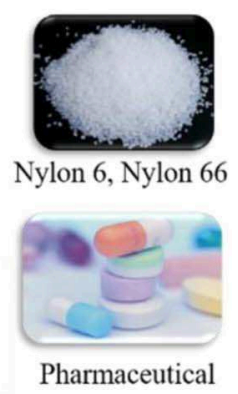

Synthetic rubber

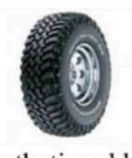

Synthe rubber

GRAPHICAL ABSTRACT | Heterogeneous Catalysts for Adipic Acid Synthesis.

show remarkable performances in AA synthesis, due to the inherent adsorptive properties and tunable acidity.

Some alternative bio-derived AA processes have been extensively reported for synthesizing AA by oxidizing lignocellulosic biomass derived chemicals, e.g., hemicellulose, cellulose, and lignin (Vardon et al., 2015; Han, 2016). Different processes including glucose to glucaric acid process, hydroxymethylfurfural (HMF) to furan dicarboxylic acid (FDCA) process, $\gamma$-valerolactone process, lignin and ligninderived oils process, were reported for AA synthesis from biomass feedstocks (Deng et al., 2016; Gunukula and Anex, 2017; Skoog et al., 2018). In the glucose conversion route, glucaric acid was formed as intermediate by oxidizing the glucose and further undergo hydrogenolysis to form AA (Zhang and Deng, 2015; Zhang and Huber, 2018). This reaction can be achieved in the presence of $\mathrm{Au}, \mathrm{Pt}$, and Pd catalysts (Ibert et al., 2002; Merbouh et al., 2002). In the FDCA process, FDCA were formed as intermediates by oxidizing the HMF and was further hydrogeneolyzed to form AA (Gilkey et al., 2018). Noble Pt and $\mathrm{Au}$ metals-based catalysts were reported most effective for this reaction (Kong et al., 2018).

Most recent review articles on the synthesis of AA have been listed in this section. Van de Vyver and Roman-Leshkov (2013), Deng et al. (2016), and Rahman et al. (2016) summarized the performances of various catalysts for AA production, with specific focus on metal catalyst design and reaction mechanism. The progress of the metabolic pathways for AA production has been reviewed (Polen et al., 2013; Alonso et al., 2015; Deng et al., 2016; Kruyer and Peralta-Yahya, 2017; Skoog et al., 2018). In 2018, Li et al. (2018) summarized the conversion of cellulose and its derivatives to various organic acids. In this mini review, the glucose and HMF processes will be reviewed systematically. We will particularly focus on the advances of the performances of metallic solid catalysts and POM catalysts for synthesis of AA from both glucose and HMF routes in past 5 years, including mechanistic insights and catalysts stability. The opportunities and challenges in the green process of AA production will be discussed.

\section{HETEROGENEOUS METALLIC CATALYST FOR GLUCSOE AND DERIVATIVES OXIDATION}

The transformation of bio-based glucose and its derivatives into AA is green and sustainable. In the first step, the glucose was oxidized to form glucaric acid which was further converted to AA by a catalytic hydrodeoxygenation (HDO) process (Figure 1A). A patent disclosed a yield of $89 \%$ of AA in the HDO process over $\mathrm{Pt} / \mathrm{Rh}$ metallic catalysts in acidic condition using acetic acid and $\mathrm{HBr}$ as solvent (Boussie et al., 2014). Lin et al. (2019) reported the deoxydehydration of cellulose-derived $\mathrm{D}$-glucaric acid to AA ester over $\mathrm{ReO}_{\mathrm{x}} / \mathrm{ZrO}_{2}-\mathrm{Pd} / \mathrm{C}$ catalysts $(\mathrm{Y}=82 \%)$. In this part, we summarized the most recent progress of glucaric acid synthesis from glucose.

In the industry, this process can be achieved in the presence of homogeneous catalysts and toxic oxidants under harsh conditions (Smith et al., 2012). The difficulty of separation and the hazardous byproducts hampered the further development of this process. Literatures have widely demonstrated the synthesis of glucaric acid over the supported noble metal catalysts, e.g., Pd, (Jin et al., 2016) Pt, (Bellardita et al., 2016; Shi et al., 2018) and Au (Wojcieszak et al., 2016; Derrien et al., 2017; Solmi et al., 2017) catalysts. Au nanoparticles were immobilized on 


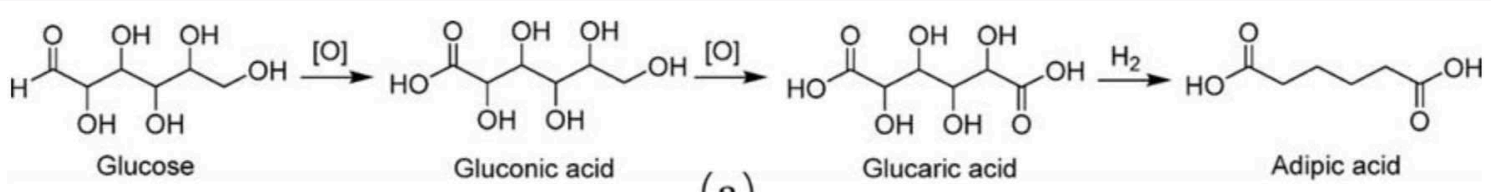

(a)

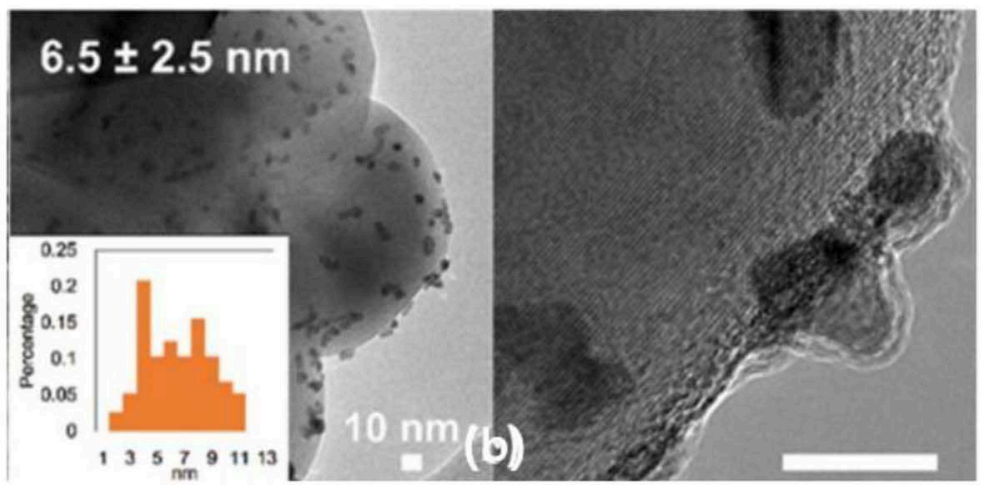

FIGURE 1 | (A) Glucose oxidation to produce AA, (Jin et al., 2016). (B) TEM images of PtPd/TiO 2 (Jin et al., 2016).

active carbon (Table 1, \#1) (Solmi et al., 2017). After adding Bi additives, AuBi/AC catalyst showed higher glucaric acid yield (Table 1, \#2). They claimed that Au particle size affected the ratio between the parallel reactions of gluconic and glucaric acid formation. The reuse study showed a little decline of the activity due to the agglomeration of nanoparticles and the deposition of organic residues (Solmi et al., 2017). Au-Pt and Au-Pd catalysts were supported on various metal oxides (Table 1, \#3) (Derrien et al., 2017). The catalytic performance of these catalysts was significantly influenced by the nature of the support. The best glucaric acid yield (44\%) was obtained in the presence of $\mathrm{ZrO}_{2}$ supported Au-Pt catalyst under base-free conditions (Derrien et al., 2017) $\mathrm{CeO}_{2}$ supported Au-Pt catalyst showed the lowest activity. They also noticed that Au-Pd showed higher ability to convert glucose to gluconic acid, but lower ability to further convert gluconic acid to glucaric acid comparing to the $\mathrm{Au}-$ Pt catalysts (Derrien et al., 2017). The recycled Au-Pt/ZrO catalyst was stable in three successive runs, but displayed lower glucaric acid selectivity in the fourth to sixth runs. The TEM images showed the particles' morphology did not change after $24 \mathrm{~h}$ reaction. ICP results showed there was no trace of $\mathrm{Au}$ or Pt presented in the reaction solution. Hence, they concluded that the activity decline was caused by the multiple handling and washing of the catalyst. The same group synthesized $\mathrm{Pt} / \mathrm{C}$ catalyst and obtained a yield of $54 \%$ of glucarate under alkaline conditions (Table 1, \#4) (Derrien et al., 2016). Lee et al. (2016) get a maximum yield of $74 \%$ of glucaric acid with $\mathrm{Pt} / \mathrm{C}$ in aqueous solution with $\mathrm{pH}$ of 7.2 using air as oxidant. They found that the selectivity to gluconic acid was higher in acidic conditions due to $\mathrm{C}-\mathrm{C}$ bond cleavage to short chain carboxylic acids (Table 1, \#5) (Lee et al., 2016). The Pt/C catalyst showed good stability in at least five consecutive runs and had no $\mathrm{Pt}$ leaching and morphology changing during the reaction. Bimetallic $\mathrm{PtPd} / \mathrm{TiO}_{2}\left(\mathrm{TOF}=2404 \mathrm{~h}^{-1}\right.$ ) catalyst was synthesized via a simple in situ reduction method and displayed much higher activity compared to monometallic catalysts (TOF $=248 \mathrm{~h}^{-1}$ ) due to the existence of PtPd alloy structure as confirmed by the TEM image (Figure 1B, Table 1, \#6) (Jin et al., 2016). The $\mathrm{PtPd} / \mathrm{TiO}_{2}$ catalyst was stable in three consecutive runs with no activity loss, but about $4 \% \mathrm{Pt}$ and Pd leaching was observed. It is highly possible that the leached metal species may be inactive in this reaction. The same group prepared $\mathrm{Pt}-\mathrm{Cu} / \mathrm{TiO}_{2}$ catalyst using $\mathrm{NaBH}_{4}$ as reducing agent and demonstrated a satisfactory activity for glucaric acid $(X=92 \%, S=60 \%)$ under base-free conditions (Table 1, \#7) (Jin et al., 2015; Shi et al., 2018). They observed strong metal-support interaction between $\mathrm{Pt}$ and $\mathrm{TiO}_{2}$ support. The stability study showed that the catalyst exhibited same conversion of glucose and marginal change of selectivity to glucaric acid after three runs. This work demonstrated that it is practicable to replace the second noble metal with inexpensive $\mathrm{Cu}$ metal for the glucose oxidation process (Shi et al., 2018).

$\mathrm{HMF}$ is an important platform chemical which can be converted to AA by two steps. HMF was oxidized to form FDCA which undergo deoxygenation to form AA. Wei et al. (2019) reported one-step conversion of FDCA to AA in water over niobic acid-supported Pt catalyst 38\% AA yield was obtained at $200^{\circ} \mathrm{C}$ in $8 \mathrm{~h}$ over $\mathrm{Pt} / \mathrm{Nb}_{2} \mathrm{O}_{5}$ catalyst which was proved to be stable in at least five repeated runs. The hydrodeoxygenation of FDCA was also conducted in the presence of $\mathrm{Pt}-\mathrm{MoO}_{\mathrm{x}} / \mathrm{TiO}_{2}$ catalyst with AA yield of $21 \%$ at $200^{\circ} \mathrm{C}$ in $4 \mathrm{~h}$ (Asano et al., 2016). The low solubility of FDCA in water may cause the low AA yield. Gilkey et al. (2017) studied the metal-free hydrogenolysis of tetrahydrofuran-2,5-dicarboxylic acid (THFDCA) to produce AA. A 99\% THFDCA conversion and $89 \%$ yield of AA were obtained at $160^{\circ} \mathrm{C}$ in $2 \mathrm{~h}$. The literatures about this step was rare, but FDCA synthesis from HMF oxidation has been widely reported as one of the key steps of biomass conversion to AA (Figure 2A) (Zhang et al., 2015, 2018; Zhou et al., 2016; Diamond 
TABLE 1 | Heterogeneous metallic catalyst for glucose and derivatives oxidation.

\begin{tabular}{|c|c|c|c|}
\hline & Catalyst & Reaction conditions & Conversion, selectivity \\
\hline 1 & $\mathrm{Au} / \mathrm{C}$ & Glucose, $60^{\circ} \mathrm{C}, 3 \mathrm{~h}, 1 \mathrm{MPa}, \mathrm{O}_{2}$ & $Y=24 \%$ \\
\hline 2 & $\mathrm{AuBi} / \mathrm{C}$ & Glucose, $60^{\circ} \mathrm{C}, 3 \mathrm{~h}, 1 \mathrm{MPa}, \mathrm{O}_{2}$ & $Y=31 \%$ \\
\hline 3 & $\mathrm{Au}-\mathrm{Pt} / \mathrm{ZrO}_{2}$ & Glucose, $100^{\circ} \mathrm{C}, 4 \mathrm{~h}, 4 \mathrm{MPa}$, air & $Y=44 \%$ \\
\hline 4 & $\mathrm{Pt} / \mathrm{C}$ & Glucose, $60^{\circ} \mathrm{C}, 24 \mathrm{~h}, 0.1 \mathrm{MPa}$, air & $Y=54 \%$ \\
\hline 5 & $\mathrm{Pt} / \mathrm{C}$ & Glucose, $80^{\circ} \mathrm{C}, 10 \mathrm{~h}, 1.4 \mathrm{MPa}, \mathrm{O}_{2}$ & $X=99 \%, S=74 \%$ \\
\hline 6 & $\mathrm{PtPd} / \mathrm{TiO}_{2}$ & Glucose, $45^{\circ} \mathrm{C}, 24 \mathrm{~h}, 0.1 \mathrm{MPa}, \mathrm{O}_{2}$ & $X=100 \%, S=40.4 \%$ \\
\hline 7 & $\mathrm{PtCu} / \mathrm{TiO}_{2}$ & Glucose, $90^{\circ} \mathrm{C}, 12 \mathrm{~h}, 1.5 \mathrm{MPa}, \mathrm{O}_{2}$ & $X=92 \%, S=60 \%$ \\
\hline 8 & AuPd/AER & $\mathrm{HMF}, 100^{\circ} \mathrm{C}, 4 \mathrm{~h}, 1 \mathrm{MPa}, \mathrm{O}_{2}$ & $X=100 \%, S=93.2 \%$ \\
\hline 9 & AuPd/CaMgAl & $\mathrm{HMF}, 100^{\circ} \mathrm{C}, 6 \mathrm{~h}, 0.5 \mathrm{MPa}, \mathrm{O}_{2}$ & $X=96.1 \%, S=89.4 \%$ \\
\hline 10 & $\mathrm{PdNi} / \mathrm{Mg}(\mathrm{OH})_{2}$ & $\mathrm{HMF}, 100^{\circ} \mathrm{C}, 10 \mathrm{~h}, 0.1 \mathrm{MPa}$, air & $X=99 \%, S=76 \%$ \\
\hline 11 & $\mathrm{PdCo} / \mathrm{Mg}(\mathrm{OH})_{2}$ & $\mathrm{HMF}, 100^{\circ} \mathrm{C}, 10 \mathrm{~h}, 0.1 \mathrm{MPa}$, air & $X=94 \%, S=46 \%$ \\
\hline 12 & $\mathrm{PdCu} / \mathrm{Mg}(\mathrm{OH})_{2}$ & $\mathrm{HMF}, 100^{\circ} \mathrm{C}, 10 \mathrm{~h}, 0.1 \mathrm{MPa}$, air & $X=81 \%, S=41 \%$ \\
\hline 13 & $\mathrm{Pt}-\mathrm{Ni} / \mathrm{AC}$ & $\mathrm{HMF}, 100^{\circ} \mathrm{C}, 6 \mathrm{~h}, 0.4 \mathrm{MPa}, \mathrm{O}_{2}$ & $X=100 \%, S=43.1 \%$ \\
\hline 14 & $\mathrm{Pt} / \mathrm{C}$ & $\mathrm{HMF}, 110^{\circ} \mathrm{C}, 12 \mathrm{~h}, 1 \mathrm{MPa}, \mathrm{O}_{2}$ & $X=99 \%, S=96 \%$ \\
\hline 15 & $\mathrm{Ru} / \mathrm{MnCO}_{2} \mathrm{O}_{4}$ & $\mathrm{HMF}, 120^{\circ} \mathrm{C}, 10 \mathrm{~h}, 2.4 \mathrm{MPa}$, air & $X=100 \%, S=99.1 \%$ \\
\hline 16 & $\mathrm{Ru} / \mathrm{HAP}$ & $\mathrm{HMF}, 120^{\circ} \mathrm{C}, 24 \mathrm{~h}, 2 \mathrm{MPa}$, air & $X=100 \%, S=99.6 \%$ \\
\hline
\end{tabular}

et al., 2018; Li et al., 2018; Rathod and Jadhav, 2018; Ventura et al., 2018). Au-Pd alloy nanoparticles were immobilized on basic anion-exchange resin and catalyzed the HMF to FDCA reaction with a yield of 93.2\% (Table 1, \#8) (Antonyraj et al., 2017). The physical mixture of $\mathrm{Au}$ and Pd nanoparticles showed only 52\% FDCA yield. This confirmed the major role of the AuPd alloy as active species as evidenced by the XPS study (Antonyraj et al., 2017). This catalyst had no metal leaching and activity decreasing after six cycles. Au-Pd alloy was also supported on La-doped CaMgAl layered double hydroxide (LDH) (Gao et al., 2017). TEM images showed that small nanoparticles with 3-4 nm particle size were well-dispersed on the LDH support (Figure 2B) (Gao et al., 2017). A yield more than $99 \%$ of FDCA was obtained ascribing to the high surface basicity of the support and the synergy between Au-Pd nanoparticles (Table 1, \#9). They also observed that the $\mathrm{La}_{2} \mathrm{O}_{3}$ on the surface of the LDH support can form carboxylic acid products and prevent the deterioration of the LDH support, thus enhance the catalyst stability (Gao et al., 2017). This catalyst maintained good activity after four runs with only $2 \%$ decreasing of the yield. No leaching of $\mathrm{Au}$ or Pd was detected. However, there were $0.8 \%$ of $\mathrm{Mg}$ and $0.3 \%$ of $\mathrm{Ca}$ lost after the reaction.

$\mathrm{Ni}, \mathrm{Co}$, and $\mathrm{Cu}$ metals were selected to synthesis bimetallic Pd catalysts. Gupta et al. $(2017 \mathrm{a}, \mathrm{b})$ found that $\mathrm{PdNi} / \mathrm{Mg}(\mathrm{OH})_{2}$ catalyst displayed higher catalytic performance than $\mathrm{Co}$ and $\mathrm{Cu}$ based $\mathrm{Pd} / \mathrm{Mg}(\mathrm{OH})_{2}$ catalyst due to the synergistic cooperation between $\mathrm{Pd}$ and $\mathrm{Ni}$ species (Table 1, \#10-12). This catalyst can be reused for three consecutive reactions without significant activity loss, $\mathrm{Pd} / \mathrm{Ni}$ metal leaching, or particle size changing. $\mathrm{Ni}$ and Pt bimetallic nanoparticles were supported on active carbon by atomic layer deposition method (Table 1, \#13) (Shen et al., 2018). The TEM images showed that the metal were uniformly dispersed on the support (Figure 2C). A 97.5\% yield of FDCA (TOF= $35.8 \mathrm{~h}^{-1}$ ) was obtained in $15 \mathrm{~h}$ reaction. They claimed that the presence of Ni species enhanced the ability of Pt to adsorb and oxidize $\mathrm{C}=\mathrm{O}$ bond (Shen et al., 2018). The catalysts recycled after four runs showed 86.3\% FDCA yield which is lower than the fresh catalysts (97.5\%). However, the reasons for the activity loss was not discussed in this work. Pt supported on carbon displayed 96\% yield of FDCA in the absence of base (Table 1, \#14) (Han et al., 2016). The introduction of $\mathrm{N}$ atom brought more medium strength basic sits to the catalyst and thus elevated the catalytic activity (Han et al., 2016). Ru immobilized on $\mathrm{MnCo}_{2} \mathrm{O}_{4}$ was reported highly active $(\mathrm{Y}=99.1 \%)$ for HMF oxidation under base-free condition (Table 1, \#15) (Mishra et al., 2017). The existence of both Lewis and BrØnsted acid sites facilitated the HMF oxidation to FDCA (Mishra et al., 2017). The reusability study showed that there was no significant change in the rate of HMF conversion in at least five successive runs. The TEM images of both fresh and used catalysts indicated that there was no discernible change of the structure. No Ru metal leaching was detected by ICP analysis.

Gao et al. (2018) supported Ru on hydroxyapatite. The TEM image showed a typical rod-shape agglomerates with the mean size of $\mathrm{Ru}$ nanoparticles about $1.8 \mathrm{~nm}$ (Figure 2D). Hundred percentage of conversion of HMF and $99.6 \%$ selectivity to FDCA were obtained in the presence of oxygen and water. The acidicbasic sites on hydroxyapatite support were essential for good catalytic performance (Table 1, \#16) (Gao et al., 2018). There was about $10 \%$ loss of the FDCA yield after the fifth runs. ICP results revealed there was no leaching of Ru and $\mathrm{Ca}$ species from the catalyst. No aggregation of $\mathrm{Ru}$ nanoparticles was noticed from the TEM images. The adsorption of impurities and the partial oxidation of Ru nanoparticles were the main reason of the catalyst deactivation.

\section{CYCLOHEXANE, AND CYCLOHEXANONE/CYCLOHEXANOL OXIDATION TO AA}

Cyclohexane and cyclohexanone/cyclohexanol are the most selected chemicals as the model substrates for oxidation reaction to produce AA over various of catalysts, such as metal oxides, carbon nano tubes (CNTs), and TS- 1 catalysts (Cavani et al., 2011; Alshammari et al., 2012; Dai et al., 2016; Chen et al., 2017; Nale et al., 2017).

\section{Cyclohexane Oxidation to AA}

Metal oxides are widely studied for oxidation reaction (Fang et al., 2013; Hao et al., 2013; Zhang et al., 2013; Li et al., 2014; Qadir et al., 2014; Gui et al., 2015; Imanaka et al., 2015; Wang et al., 2016; Shiraishi et al., 2017). The nature of the metal oxides as support or as active species influenced the catalytic performance of the catalysts significantly (Unnarkat et al., 2016; Ribeiro de Sousa Martins et al., 2017; Yang et al., 2017; Feliciano Miranda et al., 2018). Acharyya et al. (2015) synthesized $\mathrm{Cr}_{2} \mathrm{O}_{3}$ supported $\mathrm{Cu}$ nanoclusters with hydrothermal method which converted cyclohexane to cyclohexanone with high yield, but failed to produce any AA. Whereas, $\mathrm{WO}_{3}$ supported $\mathrm{Cu}$ converted cyclohexane with $88 \%$ conversion and $75 \%$ selectivity to AA (Table 2, \#1) (Acharyya et al., 2015). Most probably, the activation energy was lowered in the case of $\mathrm{Cu}-\mathrm{WO} 3$ 
A<smiles></smiles>
(FDCA)<smiles>O=C(O)C1CC(C(=O)O)C(C(=O)O)O1</smiles>
(THFDCA)<smiles>O=C(O)CCCC(O)C(=O)O</smiles>

2-hydroxyadipic acid

(HAA)<smiles>O=C(O)CCCCC(=O)O</smiles>

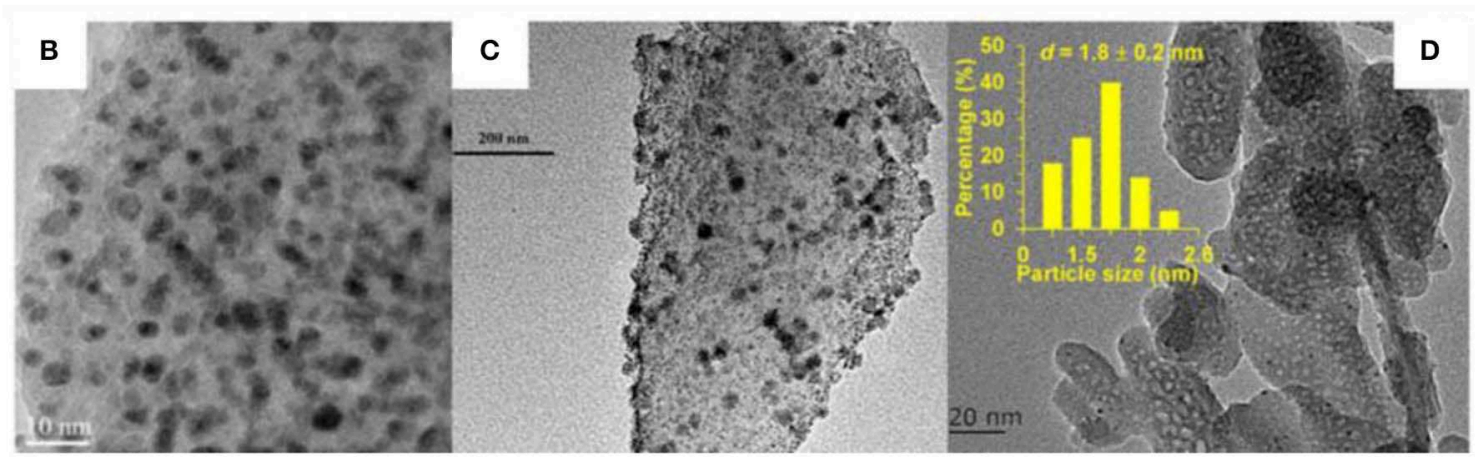

FIGURE 2 | (A) HMF to AA, (Lee et al., 2016) TEM images of (B) AuPd/CaMgAl, (Gao et al., 2017) (C) Pt-Ni/AC, (Shen et al., 2018) (D) Ru/HAP (Gao et al., 2018).

catalysts due to the flexibility property of the $\mathrm{Cu}$-framework. The impregnated $\mathrm{CuO} / \mathrm{WO}_{3}$ catalyst was inactive for cyclohexane oxidation to AA. It seems that the synergistic interaction between the $\mathrm{Cu}$ and $\mathrm{W}$ species is the main reason of the oxidation activity. Recycled $\mathrm{Cu}-\mathrm{WO}_{3}$ catalysts have no metal leaching in at least four consecutive runs without any decreasing of catalytic performance. Comparing to $\mathrm{Cu}$, $\mathrm{Au}$ has the same outermost electronic configurations but far higher activity in oxidation reactions. Liu et al. (2016) coated Au on the wall of the stainless steel microcapillary. A conversion of $2.1 \%$ and selectivity of $18.9 \%$ to AA were obtained for cyclohexane oxidation in $4 \mathrm{~min}$ (Table 2, \#2). The stability of the catalyst was not reported in this work. Alshammari et al. $(2015,2016)$ incorporated Au, $\mathrm{Pd}$, and $\mathrm{Ag}$ on $\mathrm{TiO}_{2}$ using sol-gel methods. Bimetallic catalysts $\mathrm{AuPd} / \mathrm{TiO}_{2}$ showed higher selectivity compared to monometallic $\mathrm{Pd} / \mathrm{TiO}_{2}$ toward AA (Table $2, \# 3$ ) due to smaller particle size as observed by TEM images. Au as a second metal is important for enhancing the AA selectivity due to the synergistic effects between $\mathrm{Au}$ and Pd metals. The bimetallic catalyst was observed deactivated after consecutive runs due to the formation of $\mathrm{Pd}^{\delta-}$ species with lower binding energy, metal leaching and coke formation (Alshammari et al., 2016). Chen et al. (2017) confined Au nanoparticles in hybrid shells of organic linker-assisted silica nanospheres (GOS) using amino function groups for anchoring $\mathrm{Au}$ precursor. TEM images showed that GOS has uniformed nanospheres with $120-150 \mathrm{~nm}$ diameter. The AuNPs $(<2 \mathrm{~nm})$ were highly dispersed on the shells of silica. FTIR and Raman results indicated that the incorporation of AuNPs didn't alter the structure of GOS. The obtained catalyst oxidized cyclohexane with $45 \%$ selectivity to AA under solvent-free conditions using $\mathrm{O}_{2}$ as oxidant $\left(\mathrm{TOF}=59,307 \mathrm{~h}^{-1}\right.$, Table 2 , \#4). It seems that the AuNPs confined in silica shell is more active than that in the inner cores. Besides, $\mathrm{C}-\mathrm{H}$ bonds in silica shell improved the hydrophobicity and the adsorption of cyclohexane.

Hollow structure silicates (HTS) with large intraparticle voids were more active than TS- 1 catalyst for cyclohexane oxidation reaction as reported (Shi et al., 2011). This special structure can aggravate the movement of products and reactants in and out of the channels. Zou et al. (2015b) evaluated various of HTS catalysts and found Mn-HTS gave the highest selectivity toward AA due to the nature of $\mathrm{Mn}$ metal (Table 2, \#5). The stability of Mn-HTS catalysts maintained in four runs. The stability was confirmed by comparing the FT-IR and UVVis spectra of the fresh and recycled catalysts. This reaction proceeded via radical intermediates with $\mathrm{Ti}(\mathrm{IV})-\mathrm{O} \bullet$ or $\mathrm{Ti}(\mathrm{IV})$ $\mathrm{OO} \cdot$ species as active centers and $\mathrm{Mn}^{3+}$ as promoters. $\mathrm{W}$ based HTS bifunctional catalysts showed higher activity compared to $\mathrm{H}_{2} \mathrm{WO}_{4} / \mathrm{TS}-1$ for the oxidation of cyclohexane (Table 2, \#6) due to higher accessibility of Ti species, large intraparticle voids and the bifunctional catalytic sites (Dai et al., 2016).

Carbon nanotubes (CNTs) have been widely used as catalysts support because they are insoluble in the most solvents (Coleman et al., 2006; Moniruzzaman and Winey, 2006; Tangestaninejad et al., 2008, 2009; Moghadam et al., 2010a,b). On the other hand, CNT can create confined spaces for metals to prevent the aggregation and to act as a template for metal seed growth (Moghadam et al., 2010a). Yang et al. (2016) prepared Fe-, $\mathrm{Ni}$-, and FeNi- based CNT catalysts with controllable wall 
TABLE 2 | Cyclohexane, cyclohexanol, and cyclohexanone oxidation to AA.

\begin{tabular}{|c|c|c|c|}
\hline \# & Catalyst & Reaction conditions & $\begin{array}{l}\text { Conversion, } \\
\text { selectivity }\end{array}$ \\
\hline 1 & $\mathrm{Cu}-\mathrm{WO}_{3}$ & $\begin{array}{l}\text { Cyclohexane, } 70^{\circ} \mathrm{C}, 12 \mathrm{~h} \text {, } \\
\mathrm{H}_{2} \mathrm{O}_{2}\end{array}$ & $\begin{array}{l}X=75 \%, S=88 \% \\
\text { TON }=119\end{array}$ \\
\hline 2 & $\mathrm{Au}-\mathrm{Al}_{2} \mathrm{O}_{3}$ & $\begin{array}{l}\text { Cyclohexane, } 180^{\circ} \mathrm{C} \\
0.25 \mathrm{~h}, 3 \mathrm{MPa}, \mathrm{O}_{2}\end{array}$ & $X=2.1 \%, S=18.9 \%$ \\
\hline 3 & $\mathrm{Au} / \mathrm{TiO}_{2}$ & $\begin{array}{l}\text { Cyclohexane, } 150^{\circ} \mathrm{C}, 4 \mathrm{~h} \text {, } \\
\text { TBHP, } 1 \mathrm{MPa}, \mathrm{O}_{2}\end{array}$ & $\begin{array}{l}X=25 \%, S=26 \% \\
\text { TON }=237\end{array}$ \\
\hline 4 & AuNPs(GOS) & $\begin{array}{l}\text { Cyclohexane, } 150^{\circ} \mathrm{C}, 3 \mathrm{~h} \text {, } \\
\text { TBHP }\end{array}$ & $\begin{array}{l}X=34 \%, S=45.1 \% \\
\text { TON }=59307\end{array}$ \\
\hline 5 & Mn-HTS & $\begin{array}{l}\text { Cyclohexane, } 140^{\circ} \mathrm{C}, 6 \mathrm{~h}, \\
1 \mathrm{MPa}, \mathrm{O}_{2}\end{array}$ & $\begin{array}{l}X=8.6 \%, S=57.7 \% \\
\text { TON }=324\end{array}$ \\
\hline 6 & W/HTS & $\begin{array}{l}\text { Cyclohexane, } 90^{\circ} \mathrm{C}, 14 \mathrm{~h} \text {, } \\
\mathrm{H}_{2} \mathrm{O}_{2}\end{array}$ & $\begin{array}{l}X=31.4 \%, S=78.5 \% \\
\text { TON }=31\end{array}$ \\
\hline 7 & Fe@CNT-100 & $\begin{array}{l}\text { Cyclohexane, } 125^{\circ} \mathrm{C}, 8 \mathrm{~h} \text {, } \\
1.5 \mathrm{MPa} \mathrm{O}_{2}\end{array}$ & $\begin{array}{l}X=39.7 \%, S=49.7 \% \\
\text { TON }=299\end{array}$ \\
\hline 8 & $\mathrm{M}-\mathrm{PW}_{12} \mathrm{O}_{40}$ & $\begin{array}{l}\text { Cyclohexene, } 100^{\circ} \mathrm{C} \\
72 \mathrm{~h}, \mathrm{H}_{2} \mathrm{O}_{2}\end{array}$ & $X=75 \%, Y=61 \%$ \\
\hline 9 & $\mathrm{Al}_{2} \mathrm{O}_{3} @ \mathrm{Fe}_{2} \mathrm{O}_{3}$ & $\begin{array}{l}\text { Cyclohexanone, } 80^{\circ} \mathrm{C} \text {, } \\
24 \mathrm{~h}, \mathrm{H}_{2} \mathrm{O}_{2}\end{array}$ & $\mathrm{TON}=71$ \\
\hline 10 & Mn-HTS & $\begin{array}{l}\text { Cyclohexanone, } 90^{\circ} \mathrm{C} \text {, } \\
9 \mathrm{~h}, 0.6 \mathrm{Mpa}, \mathrm{O}_{2}\end{array}$ & $\begin{array}{l}X=68 \%, S=93 \% \\
\text { TON }=713\end{array}$ \\
\hline 11 & Mn- HMTS & $\begin{array}{l}\text { Cyclohexanone, } 90^{\circ} \mathrm{C}, \\
8 \mathrm{~h}, 0.6 \mathrm{Mpa}, \mathrm{O}_{2}\end{array}$ & $\begin{array}{l}X=64 \%, S=94 \% \\
\text { TON }=887\end{array}$ \\
\hline 12 & TS-1 & $\begin{array}{l}\text { Cyclohexanone, } 80^{\circ} \mathrm{C} \text {, } \\
8 \mathrm{~h}, \mathrm{H}_{2} \mathrm{O}_{2}\end{array}$ & $\begin{array}{l}X=53 \%, S=33 \% \\
\text { TON }=34\end{array}$ \\
\hline 13 & FePO-1-2 & $\begin{array}{l}\text { Cyclohexanone, } 75^{\circ} \mathrm{C}, \\
10 \mathrm{~h}, 0.1 \mathrm{Mpa}, \mathrm{O}_{2}\end{array}$ & $\begin{array}{l}X=72 \%, S=96 \% \\
\text { TON }=42\end{array}$ \\
\hline 14 & TIPO-1 & $\begin{array}{l}\text { Cyclohexanone, } 80^{\circ} \mathrm{C} \text {, } \\
8 \mathrm{~h}, \mathrm{H}_{2} \mathrm{O}_{2}\end{array}$ & $\begin{array}{l}X=92 \%, S=66 \% \\
\text { TON }=49\end{array}$ \\
\hline 15 & MnAPO-5 & $\begin{array}{l}\text { Cyclohexanone, } \\
85^{\circ} \mathrm{C}, 72 \mathrm{~h}, \mathrm{TBHP}\end{array}$ & $\begin{array}{l}X=100 \%, S=100 \% \\
\text { TON }=566\end{array}$ \\
\hline 16 & $\mathrm{NH}_{4} \mathrm{SnPMO}_{12} \mathrm{O}_{40}$ & $\begin{array}{l}\text { Cyclohexanone, } 90^{\circ} \mathrm{C} \text {, } \\
2 \mathrm{O}, \mathrm{H}_{2} \mathrm{O}_{2}\end{array}$ & $X=100 \%, S=56$ \\
\hline 17 & $\mathrm{HNi}_{1.5} \mathrm{PMo}_{12}$ & $\begin{array}{l}\text { Cyclohexanone, } 90^{\circ} \mathrm{C} \text {, } \\
20 \mathrm{~h}, \mathrm{H}_{2} \mathrm{O}_{2}\end{array}$ & $Y=31 \%$ \\
\hline 18 & $\mathrm{CoPMO}_{12} \mathrm{O}_{40}$ & $\begin{array}{l}\text { Cyclohexanone, } 90^{\circ} \mathrm{C}, \\
20 \mathrm{~h}, \mathrm{H}_{2} \mathrm{O}_{2}\end{array}$ & $Y=75.5 \%$ \\
\hline 19 & $\mathrm{H}_{3+\mathrm{x}} \mathrm{PMO}_{12-\mathrm{x}} \mathrm{V}_{\mathrm{x}} \mathrm{O}_{40}$ & $\begin{array}{l}\text { Cyclohexanone, } 70^{\circ} \mathrm{C}, \\
12 \mathrm{~h}, 0.41 \mathrm{MPa} \text {, air }\end{array}$ & $X=16 \%, S=42 \%$ \\
\hline 20 & $\mathrm{~K}_{6} \mathrm{P}_{2} \mathrm{Mo}_{6} \mathrm{~W}_{12} \mathrm{O}_{62}$ & $\begin{array}{l}\text { Cyclohexanol, } 90^{\circ} \mathrm{C} \text {, } \\
20 \mathrm{~h}, \mathrm{H}_{2} \mathrm{O}_{2}\end{array}$ & $Y=59 \%$ \\
\hline
\end{tabular}

thickness and evaluated for cyclohexane oxidation. They found that Fe@CNT showed highest catalytic performance (Table 2, $\# 7$ ) ascribing to the thin walls of CNTs and confined electrondonating metals, which will help the electron transfer on the CNTs surfaces (Yang et al., 2016). Besides, the Fe filling can enhance the electronic property of the graphene sheets. Ni@CNT has lower activity due to the weaker interaction with carbon.

POMs were reported highly active for oxidation reaction to synthesize AA with a TON values as high as 29,550 (Luo et al., 2018) The exceptional performance of POMs was possibly due to the fact that POMs played the roles of co-catalysts, active metal sites stabilizer and electronic structure regulator in the oxidation process (Banerjee et al., 2012; Tahar et al., 2015). Keggin type POMs, were the most studied type POMs for liquid phase oxidation, due to their high resistance to oxygen donors and strong oxidizing power (Wang et al., 2015; He et al., 2016; Yu et al., 2017). Pisk et al. (2019) reported Merrifield resins supported Mo- or W- based Keggin POMs as catalysts to oxidize cyclohexene to AA with 46 and $61 \%$ yield (Table 2, $\# 8)$. They found the $\mathrm{W}$ based POMs are more active than Mo based catalysts. They proposed Baeyer-Villiger oxidation type of mechanism for this process (Figure 3A).

\section{Cyclohexanone Oxidation to AA}

Patra et al. (2013) developed a method to encapsulate $\gamma-\mathrm{Al}_{2} \mathrm{O}_{3}$ nanoparticles by a thin shell of $\alpha-\mathrm{Fe}_{2} \mathrm{O}_{3}$. The resulting material showed high surface area and meso-porosity due to selfaggregation of tiny spherical nanocrystals as confirming by SEM images. These catalysts displayed low TON for the oxidation of cyclohexanone to AA in water (Table 2, \#9), because only the surface $\mathrm{Fe}$ center took part in the reaction. A single layer of $\mathrm{Fe}$ center on the surface of the core was believed to enhance the performance of the catalysts.

Mn-HTS catalysts displayed the good performance with 68\% cyclohexanone conversion, 93\% AA selectivity (Table 2, \#10) (Zou et al., 2015a). Mn-HTS, with high oxidation states, had less BrØnsted acid sites than Lewis acid sites which favored the formation of enolate from the keto-form of cyclohexanone (Zou et al., 2015a). The recycled catalysts were shown to maintain the same $\mathrm{Mn}$ and $\mathrm{Ti}$ content in about 15 cycles of reuse. They also noticed that the use of acetic acid as the co-solvent can form $\mathrm{CH}_{3} \mathrm{COOOH}$ as oxidizing species and thus improve the reaction rate and AA selectivity. Some other groups also noticed the same phenomenon and claimed that the reaction proceed via a radical-chain autoxidation mechanism, rather than a redox mechanism in the presence of acetic acid (Shimizu et al., 2003; Cavani et al., 2011). On the other hand, acetic acid can stabilize the $\mathrm{H}_{2} \mathrm{O}_{2}$ and prevent the decomposition (Chavan et al., 2002; Shimizu et al., 2003). Gao's group prepared Mn-HMTS catalyst by a one-step hydrothermal approach with tunable textural properties (Table 2, \#11, TON = 887) (Gao et al., 2019). They noticed that the textural and physicochemical properties of $\mathrm{Mn}$ HMTS can be easily tuned by modifying the amounts of the template agent. Free-radical mechanism was proposed, since $\mathrm{Mn}$ species acted as a promoter for both radical intermediates and enol formation from cyclohexanone (Gao et al., 2019). Xia’s group also studied TS-1 catalysts for cyclohexanone oxidation reaction by combining density function theory (DFT) calculation with experimental studies (Table 2, \#12) (Xia et al., 2015). DFT calculations indicated that $\mathrm{H}_{2} \mathrm{O}_{2}$ molecule was absorbed and activated at the tetrahedral Ti sites.

Phosphonate based metal catalysts have immense potential to be used as ecofriendly catalysts due to the high durability and thermal stability (Zhao et al., 2006; Deng et al., 2011; Dutta et al., 2012; Mahdavi and Hasheminasab, 2015; Xiao et al., 2016; Rezaei et al., 2017). Bhanja et al. (2016) synthesized an organicinorganic hybrid iron phosphonate materials (FePO-1-2) via a hydrothermal synthesis route. This material displayed high activity for the cyclohexanone oxidation due to the high surface acidity as well as the framework redox $\mathrm{Fe}^{\mathrm{II} / \mathrm{III}}$ sites (Table 2, \#13). They also observed that water show more remarkable 


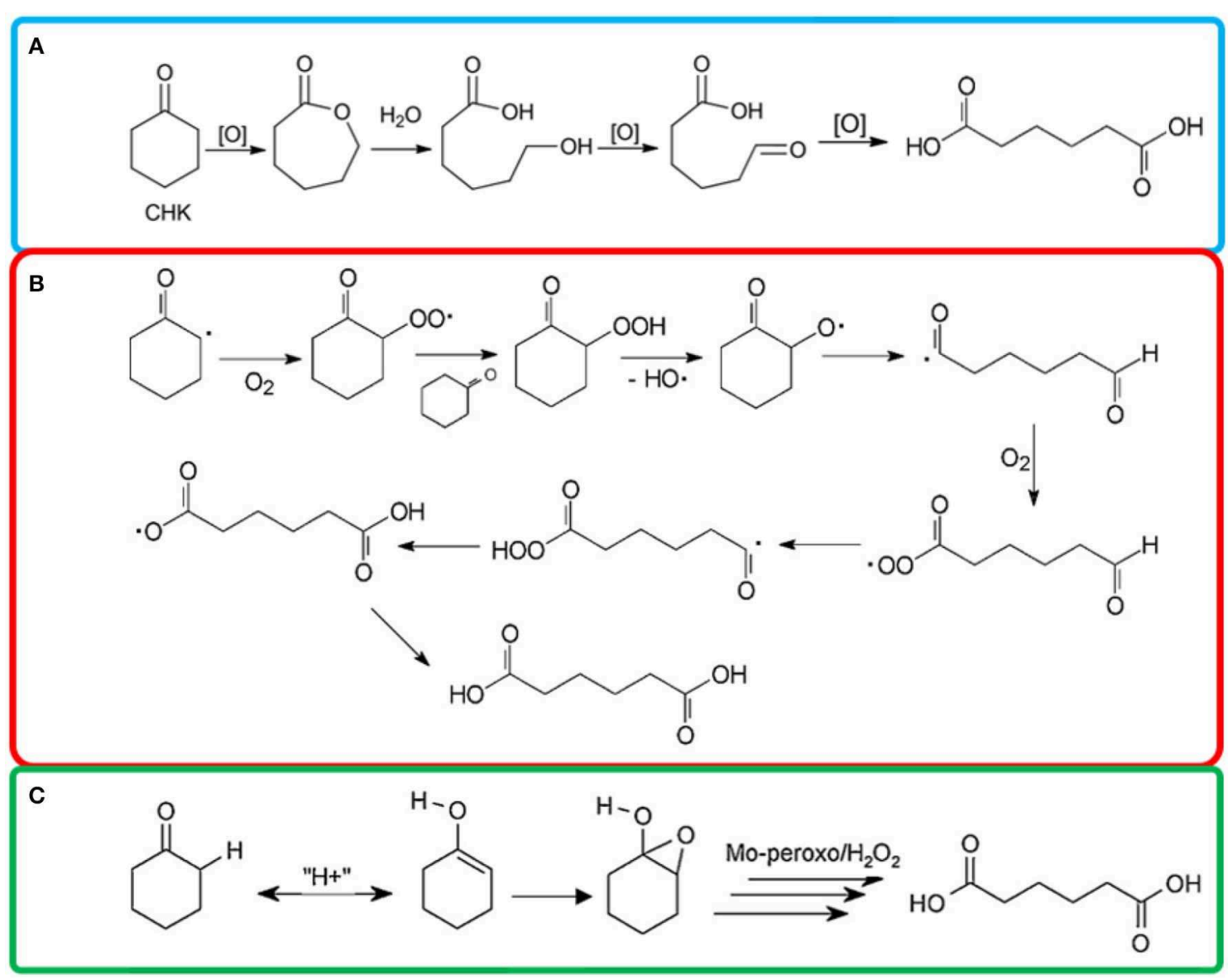

FIGURE 3 | Proposed (A) Baeyer-Villiger oxidation type of mechanism, (Pisk et al., 2019) (B) radical chain autoxidation mechanism, (Cavani et al., 2011) (C) redox mechanism (Amitouche et al., 2018) of cyclohexanone oxidation to AA.

promotion effect and good AA selectivity due to the higher polarity than other solvents (Bhanja et al., 2016). There was only very slight decrease of the AA yield after six consecutive reactions. The XRD results suggested there was only minor decrease in the crystallinity and BET surface area. There was no detectable Fe leaching from the catalyst. Later, the same group developed a oxyfluorinated titanium phosphate material (TIPO-1, Table 2, \#14) (Bhanja et al., 2018). This material showed a 92\% cyclohexanone conversion and $66 \%$ selectivity to AA. A Mn incorporating aluminophosphate material (MnAPO-5) was synthesized by Chatterjee's group (Chatterjee et al., 2018). A complete conversion of cyclohexanone and AA selectivity were obtained (Table 2, \#15). The detected $\varepsilon$-caprolactone as intermediate by ${ }^{1} \mathrm{H}$ NMR. They proposed a reaction pathway that $\varepsilon$-caprolactone formed by Baeyer-Villiger oxidation and then the ring undergoes oxidative $\mathrm{C}-\mathrm{C}$ bound cleavage to give $\mathrm{AA}$. No leaching of Mn was detected at the end of each run.

Mouheb et al. (2018) synthesized Keggin-type POMs (Table 2, \#16) and revealed that the active species for cyclohexanone oxidation might be the peroxo-polyoxometalates (Mouheb et al., 2018). On the other hand, more unidentified products formed when cyclohexanol was used as substrate. This catalyst can be reused at least 3 times without regeneration. Amitouche et al. (2018) synthesized Keggin heteropolyacid catalyst. They disclosed the pathways to different $\mathrm{H}_{3} \mathrm{PMo}_{12} \mathrm{O}_{40}$ reduced state and the transformation into peroxomolybdate complexes (Amitouche et al., 2018). As shown in Figure 3B, the $\mathrm{H}$ abstraction at the carbon next to the oxygen in cyclohexanone can be promoted in the presence of active species, and the production of radical reacted with oxygen and formed cyclohexyl hydroperoxide (Zou et al., 2015a). The ketonyl radical underwent ring opening via $\mathrm{C}-\mathrm{C}$ cleavage and formed $\mathrm{OHC}-\left(\mathrm{CH}_{2}\right)_{4}-\mathrm{C}(\mathrm{O})$ radical species (Amitouche et al., 2018). The last step was oxidation that lead to the formation of $\mathrm{AA} . \mathrm{H}_{3-2 \mathrm{x}} \mathrm{Ni}_{\mathrm{X}} \mathrm{PMo}_{12} \mathrm{O}_{40}$ catalysts showed AA yield of 31\% (Table 2, \#17) (Tahar et al., 2015). The results showed that the AA yield was sensitive to the chemical composition and the $\mathrm{x}$ value. $\mathrm{H}_{3-2 \mathrm{x}} \mathrm{Co}_{\mathrm{x}} \mathrm{PMo}_{12} \mathrm{O}_{40}$ (x: $0-1.5)$ catalysts were prepared using the cationic exchange method (Benadji et al., 2013). The cobalt salts were more effective than parent acid to oxidize cyclohexanone $(X=$ $76 \%)$ and cyclohexanol $(X=53 \%)$ because the Co-based POMs acted as acidifying and oxidizing agent (Table 2, \#18). $\mathrm{H}_{3+\mathrm{x}} \mathrm{PMo}_{12-\mathrm{x}} \mathrm{V}_{\mathrm{x}} \mathrm{O}_{40}$ catalyzed cyclohexanone oxidation via a redox mechanism and the reoxidation of the reduced POM 
was the rate-limiting step (Table 2, \#19) (Cavani et al., 2011). However, when an acetic acid was used as additive, a radical chain autoxidation mechanism prevailed. The metal composition of the POMs affected the relative importance of the two mechanism (Figures 3B,C). The radical chain autoxidation mechanism was more selective to AA than the redox mechanism, because in the radical chain autoxidation mechanism there was no intermediate of partially oxidized products (lighter acids and $\mathrm{CO}_{2}$ ) formed (Cavani et al., 2011).

Anderson and Dawson type POMs were also reported active for oxidation reactions. Luo et al. (2018) synthesized a POMs nanoclusters with butterfly-shaped $\beta$ isomer. This catalyst displayed good activity (TON: 29,550) toward AA in solvent free condition. When cyclohexanol was used as substrate, the AA yield was lower than the cyclohexanone. The recycle ability study indicated that there was an appreciable loss of AA yield after three runs. Dawson-type POMs $\left(\mathrm{P}_{2} \mathrm{M}_{18}\right)$ have potential to have oxidation properties since they have more elements with a high oxidation state than that of the Keggin anion (Moudjahed et al., 2016). Moudjahed et al. (2016) prepared Dawson-type POMs which showed an AA yield of $69 \%$ in the KA oil oxidation reaction (Table 2, \#20). ${ }^{31} \mathrm{P}$ NMR spectroscopy of used POMs confirmed the formation of "peroxo-POMox" as active intermediate species.

\section{CONCLUSION}

Based on the critical review, biomass-based AA provides important and alternative routes for future development of nylon industry. At present, selective oxidation of sugars and derivatives to relevant aldaric acids is the key challenge in this area. Future work should be focused on finding more effective and inexpensive materials to achieve this chemistry. The progress and potential significance of nanostructured solid catalysts and POMs catalysts for oxidation of cyclohexane, cyclohexene, cyclohexanol and cyclohexanone to produce AA with green oxidants have been critically revised in this paper. This work summarized and discussed catalysts synthesis and

\section{REFERENCES}

Acharyya, S. S., Ghosh, S., and Bal, R. (2015). Nanoclusters of $\mathrm{Cu}(\mathrm{II})$ supported on nanocrystalline $\mathrm{W}(\mathrm{VI})$ oxide: a potential catalyst for singlestep conversion of cyclohexane to adipic acid. Green Chem. 17, 3490-3499. doi: 10.1039/C5GC00379B

Alonso, S., Rendueles, M., and Diaz, M. (2015). Microbial production of specialty organic acids from renewable and waste materials. Crit. Rev. Biotechnol. 35, 497-513. doi: 10.3109/07388551.2014.904269

Alshammari, A., Kalevaru, V. N., and Martin, A. (2016). Bimetallic catalysts containing gold and palladium for environmentally important reactions. Catalysts 6:24. doi: 10.3390/catal6070097

Alshammari, A., Koeckritz, A., Kalevaru, V. N., Bagabas, A., and Martin, A. (2012). Significant formation of adipic acid by direct oxidation of cyclohexane using supported nano-gold catalysts. Chemcatchem 4, 1330-1336. doi: $10.1002 /$ cctc. 201200008

Alshammari, A., Koeckritz, A., Kalevaru, V. N., Bagabas, A., and Martin, A. (2015). Potential of supported gold bimetallic catalysts for green synthesis of adipic acid from cyclohexane. Top. Catal. 58, 1069-1076. doi: 10.1007/s11244-015-0475-9 structural characterization, the oxidation reaction mechanism, as well as catalyst durability. The POMs with dual redox and acidity properties display high catalytic activity and selectivity for cyclohexane/cyclohexene/cyclohexanone/cyclohexanol oxidation. Important accomplishments in this research area could be further achieved by the efficient catalyst design, and a deep understanding of both redox and radical based oxidation mechanisms.

Fundamental understanding of catalysts deactivation and oxidant utilization efficiency improvement should be the focusing efforts in the future study. The economic and environment analysis of the new green processes are needed to systematically study to see if the green processes has the potential to replace in the current industrial process. This work provides guidance for further investigation on metal nano catalysts for the efficient, green, safe, sustainable, ecofriendly and economical route of AA production and oxidation processes for many other value-added fine chemicals production.

\section{AUTHOR CONTRIBUTIONS}

WY drafted the manuscript. XJ conceived the concept of the review. GZ, JW, and ML conducted literature survey. YS, ZZ, $\mathrm{WZ}$, and SZ organized figures and revised the manuscript. XX and JS provided comments.

\section{FUNDING}

This work was supported by the National Natural Science Foundation (21706290), Natural Science Foundation of Shandong Province (ZR2017BB007 and ZR2017MB004), Postdoctoral Research Funding of Shandong Province (201703016), Qingdao Postdoctoral Research Funding (BY20170210), Fundamental Research Funding of Qingdao (171-1-67-jch and 17-1-1-80-jch), the Fundamental Research Funds for the Central Universities (18CX02145A and 17CX02017A), and new faculty start-up funding from China University of Petroleum (YJ201601058).
Amitouche, D., Haouas, M., Mazari, T., Mouanni, S., Canioni, R., Rabia, C., et al. (2018). The primary stages of polyoxomolybdate catalyzed cyclohexanone oxidation by hydrogen peroxide as investigated by in situ NMR. Substrate activation and evolution of the working catalyst. Appl. Catal. A 561, 104-116. doi: 10.1016/j.apcata.2018. 05.017

Antonyraj, C. A., Huynh, N. T. T., Park, S. K., Shin, S., Kim, Y. J., Kim, S., et al. (2017). Basic anion-exchange resin (AER)-supported Au-Pd alloy nanoparticles for the oxidation of 5-hydroxymethyl-2-furfural (HMF) into 2,5-furan dicarboxylic acid (FDCA). Appl. Catal. A 547, 230-236. doi: 10.1016/j.apcata.2017.09.012

Asano, T., Tamura, M., Nakagawa, Y., and Tomishige, K. (2016). Selective hydrodeoxygenation of 2-furancarboxylic acid to valeric acid over molybdenum-oxide-modified platinum catalyst. ACS Sustain. Chem. Eng. 4, 6253-6257. doi: 10.1021/acssuschemeng.6b 01640

Baig, R. B. N., and Varma, R. S. (2012). Alternative energy input: mechanochemical, microwave and ultrasound-assisted organic synthesis. Chem. Soc. Rev. 41, 1559-1584. doi: 10.1039/C1CS15204A 
Banerjee, A., Bassil, B. S., Röschenthaler, G. V., and Kortz, U. (2012). Diphosphates and diphosphonates in polyoxometalate chemistry. Chem. Soc. Rev. 41, 7590-7604. doi: 10.1039/c2cs35153f

Bellardita, M., Garcia-Lopez, E. I., Marci, G., and Palmisano, L. (2016). Photocatalytic formation of $\mathrm{H}_{2}$ and value-added chemicals in aqueous glucose (Pt)- $\mathrm{TiO}_{2}$ suspension. Int. J. Hydrogen Energy 41, 5934-5947. doi: 10.1016/j.ijhydene.2016.02.103

Benadji, S., Mazari, T., Dermeche, L., Salhi, N., Cadot, E., and Rabia, C. (2013). Clean alternative for adipic acid synthesis via liquid-phase oxidation of cyclohexanone and cyclohexanol over H3-2xCoxPMo12O40 catalysts with hydrogen peroxide. Catal. Lett. 143, 749-755. doi: 10.1007/s10562-013-1025-3

Bhanja, P., Chatterjee, S., Patra, A. K., and Bhaumik, A. (2018). A new microporous oxyfluorinated titanium(IV) phosphate as an efficient heterogeneous catalyst for the selective oxidation of cyclohexanone. J. Colloid Interfaces Sci. 511, 92-100. doi: 10.1016/j.jcis.2017.09.115

Bhanja, P., Ghosh, K., Islam, S. S., Patra, A. K., Islam, S. M., and Bhaumik, A. (2016). New hybrid iron phosphonate material as an efficient catalyst for the synthesis of adipic acid in air and water. ACS Sustain. Chem. Eng. 4, 7147-7157. doi: 10.1021/acssuschemeng.6b02023

Boussie, T. R., Dias, E. L., Fresco, Z. M., Murphy, V. J., Shoemaker, J., Archer, R., et al. (2014). Production of Adipic Acid and Dericatives From CarbotydrateContaining Materials. U.S. Patent No: US8669397B2.

Cavani, F., Ferroni, L., Frattini, A., Lucarelli, C., Mazzini, A., Raabova, K., et al. (2011). Evidence for the presence of alternative mechanisms in the oxidation of cyclohexanone to adipic acid with oxygen, catalysed by Keggin polyoxometalates. Appl. Catal. A 391, 118-124. doi: 10.1016/j.apcata.2010. 04.032

Chatterjee, S., Bhanja, P., Paul, L., Ali, M., and Bhaumik, A. (2018). MnAPO-5 as an efficient heterogeneous catalyst for selective liquid phase partial oxidation reactions. Dalton Trans. 47, 791-798. doi: 10.1039/C7DT03897F

Chavan, S. A., Srinivas, D., and Ratnasamy, P. (2002). Oxidation of cyclohexane, cyclohexanone, and cyclohexanol to adipic acid by a non-HNO3 route over Co/Mn cluster complexes. J. Catal. 212, 39-45. doi: 10.1006/jcat.200 2.3756

Chen, L., Zhou, Y., Gui, Z., Cheng, H., and Qi, Z. (2017). Au nanoparticles confined in hybrid shells of silica nanospheres for solvent-free aerobic cyclohexane oxidation. J. Mater. Sci. 52, 7186-7198. doi: 10.1007/s10853-017-0954-4

Cheng, C. Y., Lin, K. J., Prasad, M. R., Fu, S. J., Chang, S. Y., Shyu, S. G., et al. (2007). Synthesis of a reusable oxotungsten-containing SBA-15 mesoporous catalyst for the organic solvent-free conversion of cyclohexene to adipic acid. Catal. Commun. 8, 1060-1064. doi: 10.1016/j.catcom.2006.10.027

Coleman, J. N., Khan, U., Blau, W. J., and Gun'ko, Y. K. (2006). Small but strong: a review of the mechanical properties of carbon nanotube-polymer composites. Carbon 44, 1624-1652. doi: 10.1016/j.carbon.2006.02.038

Dai, J., Zhong, W., Yi, W., Liu, M., Mao, L., Xu, Q., et al. (2016). Bifunctional $\mathrm{H}_{2} \mathrm{WO}_{4} / \mathrm{TS}-1$ catalysts for direct conversion of cyclohexane to adipic acid: active sites and reaction steps. Appl. Catal. B 192, 325-341. doi: 10.1016/j.apcatb.2016.04.005

Deng, Y., Chen, B., Wu, J., Yuan, X., and Luo, H. (2011). Effect of calcination atmosphere on the catalytic performance of MNAPO-36 molecular sieve. Petrochem. Technol. 40, 247-250.

Deng, Y., Ma, L., and Mao, Y. (2016). Biological production of adipic acid from renewable substrates: current and future methods. Chem. Eng. J. 105, 16-26. doi: 10.1016/j.bej.2015.08.015

Derrien, E., Marion, P., Pinel, C., and Besson, M. (2016). Influence of residues contained in softwood hemicellulose hydrolysates on the catalytic oxidation of glucose to glucarate in alkaline aqueous solution. Org. Process Res. Dev. 20, 1265-1275. doi: 10.1021/acs.oprd.6b00095

Derrien, E., Mounguengui-Diallo, M., Perret, N., Marion, P., Pinel, C., and Besson, M. (2017). Aerobic oxidation of glucose to glucaric acid under alkaline-free conditions: au-based bimetallic catalysts and the effect of residues in a hemicellulose hydrolysate. Ind. Eng. Chem. Res. 56, 13176-13190. doi: $10.1021 /$ acs.iecr.7b01571

Diamond, G., Hagemeyer, A., Murphy, V., and Sokolovskii, V. (2018). Catalytic conversion of biorenewable sugar feedstocks into market chemicals. Comb. Chem. High Throughput Screen. 21, 616-630. doi: 10.2174/1386207322666181219155050
Dugal, M., Sankar, G., Raja, R., and Thomas, J. M. (2000). Designing a heterogeneous catalyst for the production of adipic acid by aerial oxidation of cyclohexane. Angew. Chem. Int. Ed. 39, 2310-2313. doi: 10.1002/1521-3773(20000703)39:13<2310::AID-ANIE2310>3.0.CO;2-G

Dutta, A., Pramanik, M., Patra, A. K., Nandi, M., Uyama, H., and Bhaumik, A. (2012). Hybrid porous tin(IV) phosphonate: an efficient catalyst for adipic acid synthesis and a very good adsorbent for $\mathrm{CO} 2$ uptake. Chem. Commun. 48, 6738-6740. doi: 10.1039/c2cc32298f

Fang, X., Li, X., Hao, Z., He, J., and Chen, D. (2013). Preparation of complex oxide WO_3-SNO_2 for catalytic synthesis of adipic acid. Chem. World 54, 328-331. Feliciano Miranda, J., Cuesta Zapata, P. M., Gonzo, E. E., Parentis, M. L., Davies, L. E., and Bonini, N. A. (2018). Amorphous $\mathrm{Cr} / \mathrm{SiO} 2$ materials hydrothermally treated: liquid phase cyclohexanol oxidation. Catal. Lett. 148, 2082-2094. doi: 10.1007/s10562-018-2422-4

Feng, J., Li, M., and Meng, X. (2019). Green oxidation of cyclohexanone to adipic acid over phosphotungstic acid encapsulated in UiO-66. Catal. Lett. 149, 1504-1512. doi: 10.1007/s10562-019-02764-0

Fujitani, K., Mizutani, T., Oida, T., and Kawase, T. (2009). Oxidative cleavage with hydrogen peroxide: preparation of polycarboxylic acids from cyclic olefins. $J$. Oleo Sci. 58, 37-42. doi: 10.5650/jos.58.37

Gao, T., Yin, Y., Fang, W., and Cao, Q. (2018). Highly dispersed ruthenium nanoparticles on hydroxyapatite as selective and reusable catalyst for aerobic oxidation of 5-hydroxymethylfurfural to 2, 5-furandicarboxylic acid under base-free conditions. Mol. Catal. 450, 55-64. doi: 10.1016/j.mcat.2018. 03.006

Gao, X., Zhou, Y., Gu, J., Li, L., and Li, Y. (2019). Facile synthesis of hierarchical manganese-containing TS-1 and its application on the oxidation of cyclohexanone with molecular oxygen. Microporous Mesoporous Mater. 275, 263-269. doi: 10.1016/j.micromeso.2018.08.037

Gao, Z., Xie, R., Fan, G., Yang, L., and Li, F. (2017). Highly efficient and stable bimetallic aupd over la-doped ca-mg-al layered double hydroxide for base-free aerobic oxidation of 5-hydroxymethylfurfural in water. ACS Sustain. Chem. Eng. 5, 5852-5861. doi: 10.1021/acssuschemeng.7b 00573

Gilkey, M. J., Balakumar, R., Vlachos, D. G., and Xu, B. (2018). Adipic acid production catalyzed by a combination of a solid acid and an iodide salt from biomass-derived tetrahydrofuran-2,5-dicarboxylic acid. Catal. Sci. Technol. 8, 2661-2671. doi: 10.1039/C8CY00379C

Gilkey, M. J., Mironenko, A. V., Vlachos, D. G., and Xu, B. (2017). Adipic acid production via metal-free selective hydrogenolysis of biomassderived tetrahydrofuran-2,5-dicarboxylic acid. ACS Catal. 7, 6619-6634. doi: $10.1021 /$ acscatal.7b01753

Gui, Z., Cao, W., Chen, L., and Qi, Z. (2015). Propene carbonate intensified cyclohexane oxidation over $\mathrm{Au} / \mathrm{SiO} 2$ catalyst. Catal. Commun. 64, 58-61. doi: 10.1016/j.catcom.2015.02.001

Gunukula, S., and Anex, R. P. (2017). Techno-economic analysis of multiple bio-based routes to adipic acid. Biofuel. Bioprod. Biorefin 11, 897-907. doi: 10.1002/bbb.1797

Gupta, K., Rai, R. K., Dwivedi, A. D., and Singh, S. K. (2017a). Catalytic aerial oxidation of biomass-derived furans to furan carboxylic acids in water over bimetallic nickel-palladium alloy nanoparticles. Chemcatchem 9, 2760-2767. doi: $10.1002 /$ cctc. 201600942

Gupta, K., Rai, R. K., and Singh, S. K. (2017b). Catalytic aerial oxidation of 5-hydroxymethyl-2-furfural to furan-2,5-dicarboxylic acid over Ni-Pd nanoparticles supported on $\mathrm{Mg}(\mathrm{OH})(2)$ nanoflakes for the synthesis of furan diesters. Inorg. Chem. Front. 4, 871-880. doi: 10.1039/C7QI00026J

Han, J. (2016). A bio-based 'green' process for catalytic adipic acid production from lignocellulosic biomass using cellulose and hemicellulose derived gamma-valerolactone. Energy Convers. Manage. 129, 75-80. doi: 10.1016/j.enconman.2016.10.019

Han, X., Li, C., Guo, Y., Liu, X., Zhang, Y., and Wang, Y. (2016). $\mathrm{N}$-doped carbon supported Pt catalyst for base-free oxidation of 5hydroxymethylfurfural to 2,5-furandicarboxylic acid. Appl. Catal. A 526, 1-8. doi: 10.1016/j.apcata.2016.07.011

Hao, Z., Yang, H., He, J., and Chen, D. (2013). Preparation of WO3/SiO2 catalyst for green oxidation of cyclohexanone to adipic acid with $\mathrm{H}_{2} \mathrm{O}_{2}$. Appl. Chem. Ind. $42,245-247$. 
He, P., Xu, B., Xu, X., Song, L., and Wang, X. (2016). Surfactant encapsulated palladium-polyoxometalates: controlled assembly and their application as single-atom catalysts. Chem. Sci. 7, 1011-1015. doi: 10.1039/C5SC03554F

Hereijgers, B. P. C., and Weckhuysen, B. M. (2010). Aerobic oxidation of cyclohexane by gold-based catalysts: new mechanistic insight by thorough product analysis. J. Catal. 270, 16-25. doi: 10.1016/j.jcat.2009.12.003

Ibert, M., Marsais, F., Merbouh, N., and Bruckner, C. (2002). Determination of the side-products formed during the nitroxide-mediated bleach oxidation of glucose to glucaric acid. Carbohydr. Res. 337, 1059-1063. doi: 10.1016/S0008-6215(02)00072-1

Imanaka, N., Masui, T., and Jyoko, K. (2015). Selective liquid phase oxidation of cyclohexane over $\mathrm{Pt} / \mathrm{CeO}_{2}-\mathrm{ZrO}_{2}-\mathrm{SnO}_{2} / \mathrm{SiO}_{2}$ catalysts with molecular oxygen. J. Adv. Ceram. 4, 111-117. doi: 10.1007/s40145-015-0138-0

Indulkar, U. U., Kale, S. R., Gawande, M. B., and Jayaram, R. V. (2012). Ecofriendly and facile nano $\mathrm{ZnO}$ catalyzed solvent-free enamination of 1,3-dicarbonyls. Tetrahedron Lett. 53, 3857-3860. doi: 10.1016/j.tetlet.2012.05.048

Jin, P., Zhao, Z., Dai, Z., Wei, D., Tang, M., and Wang, X. (2011). Influence of reaction conditions on product distribution in the green oxidation of cyclohexene to adipic acid with hydrogen peroxide. Catal. Today 175, 619-624. doi: 10.1016/j.cattod.2011.04.041

Jin, X., Zhao, M., Shen, J., Yan, W., He, L., Thapa, P. S., et al. (2015). Exceptional performance of bimetallic $\mathrm{Pt}_{1} \mathrm{Cu}_{3} / \mathrm{TiO}_{2}$ nanocatalysts for oxidation of gluconic acid and glucose with $\mathrm{O}_{2}$ to glucaric acid. J. Catal. 330, 323-329. doi: 10.1016/j.jcat.2015.05.018

Jin, X., Zhao, M., Vora, M., Shen, J., Zeng, C., Yan, W., et al. (2016). Synergistic effects of bimetallic $\mathrm{PtPd} / \mathrm{TiO}_{2}$ nanocatalysts in oxidation of glucose to glucaric acid: structure dependent activity and selectivity. Ind. Eng. Chem. Res. 55, 2932-2945. doi: 10.1021/acs.iecr.5b04841

Kong, X., Zhu, Y., Fang, Z., Kozinski, J. A., Butler, I. S., Xu, L., et al. (2018). Catalytic conversion of 5-hydroxymethylfurfural to some value-added derivatives. Green Chem. 20, 3657-3682. doi: 10.1039/C8GC00234G

Kruyer, N. S., and Peralta-Yahya, P. (2017). Metabolic engineering strategies to bio-adipic acid production. Curr. Opin. Biotechnol. 45, 136-143. doi: 10.1016/j.copbio.2017.03.006

Lee, J., Saha, B., and Vlachos, D. G. (2016). Pt catalysts for efficient aerobic oxidation of glucose to glucaric acid in water. Green Chem. 18, 3815-3822. doi: $10.1039 / \mathrm{C} 6 \mathrm{GC} 00460 \mathrm{~A}$

Li, S., Deng, W., Wang, S., Wang, P., An, D., Li, Y., et al. (2018). Catalytic transformation of cellulose and its derivatives into functionalized organic acids. Chemsuschem 11, 1995-2028. doi: 10.1002/cssc.201800440

Li, X., Tian, Y., Li, J., Chen, D., and Li, M. (2014). Hydrothermal preparation of tungsten-based catalyst Sn-dopedfor catalytic synthesis of adipic acid. Appl. Chem. Ind. 43, 1050-1053.

Lin, J., Song, H., Shen, X., Wang, B., Xie, S., Deng, W., et al. (2019). Zirconia-supported rhenium oxide as an efficient catalyst for the synthesis of biomass-based adipic acid ester. Chem. Commun. 55, 11017-11020. doi: 10.1039/C9CC05413H

Liu, Y., Zhu, M. Q., Chen, X. Z., Jameel, U., and Lu, J. G. (2016). Coating of Au$\mathrm{Al}_{2} \mathrm{O}_{3}$ catalyst in the wall of microcapillary and its application in cyclohexane oxidation. J. Flow Chem. 6, 110-116. doi: 10.1556/1846.2015.00007

Lu, X. H., Yuan, H. X., Lei, J., Zhang, J. L., Yu, A. A., Zhou, D., et al. (2012). Selective oxidation of cyclohexane to KA-oil with oxygen over active Co $3 \mathrm{O}$ 4 in a solvent-free system. Indian J. Chem. Sect. A 51, 420-427.

Luo, J., Huang, Y., Ding, B., Wang, P., Geng, X., Zhang, J., et al. (2018). Single-atom $\mathrm{MN}$ active site in a triol-stabilized beta-anderson manganohexamolybdate for enhanced catalytic activity towards adipic acid production. Catalysts 8:121. doi: $10.3390 /$ catal 8030121

Machado, K., Mishra, J., Suzuki, S., and Mishra, G. S. (2014). Synthesis of superparamagnetic carbon nanotubes immobilized Pt and Pd pincer complexes: highly active and selective catalysts towards cyclohexane oxidation with dioxygen. Dalton Trans. 43, 17475-17482. doi: 10.1039/C4DT02099E

Mahdavi, V., and Hasheminasab, H. R. (2015). Liquid-phase efficient oxidation of cyclohexane over cobalt promoted VPO catalyst using tert-butylhydroperoxide. J. Taiwan Inst. Chem. Eng. 51, 53-62. doi: 10.1016/j.jtice.2015.01.020

Makgwane, P. R., and Ray, S. S. (2014). Efficient room temperature oxidation of cyclohexane over highly active hetero-mixed $\mathrm{WO}_{3} / \mathrm{V}_{2} \mathrm{O}_{5}$ oxide catalyst. Catal. Commun. 54, 118-123. doi: 10.1016/j.catcom.2014.05.031
Mazzi, A., Paul, S., Cavani, F., and Wojcieszak, R. (2018). Cyclohexane oxidation to adipic acid under green conditions: a scalable and sustainable process. Chemcatchem 10, 3680-3682. doi: 10.1002/cctc.2018 00419

Merbouh, N., Bobbitt, J. M., and Bruckner, C. (2002). 4-AcNH-TEMPO-catalyzed oxidation of aldoses to aldaric acids using chlorine or bromine as terminal oxidants. J. Carbohydr. Chem. 21, 65-77. doi: 10.1081/CAR-120003738

Mishra, D. K., Lee, H. J., Kim, J., Lee, H. S., Cho, J. K., Suh, Y.-W., et al. (2017). $\mathrm{MnCo}_{2} \mathrm{O}_{4}$ spinel supported ruthenium catalyst for air-oxidation of HMF to FDCA under aqueous phase and base-free conditions. Green Chem. 19, 1619-1623. doi: 10.1039/C7GC00027H

Moghadam, M., Tangestaninejad, S., Mirkhani, V., Mohammadpoor-Baltork, I., and Mirbagheri, N. S. (2010a). Molybdenum hexacarbonyl supported on functionalized multi-wall carbon nanotubes: efficient and highly reusable catalysts for epoxidation of alkenes with tert-butyl hydroperoxide. J. Organomet. Chem. 695, 2014-2021. doi: 10.1016/j.jorganchem.2010.05.008

Moghadam, M., Tangestaninejad, S., Mirkhani, V., Mohammadpoor-Baltork, I., Mirjafari, A., and Mirbagheri, N. S. (2010b). Multi-wall carbon nanotubes supported molybdenum hexacarbonyl: an efficient and highly reusable catalyst for epoxidation of alkenes with tert-butyl hydroperoxide. J. Mol. Catal. A Chem. 329, 44-49. doi: 10.1016/j.molcata.2010.06.016

Moniruzzaman, M., and Winey, K. I. (2006). Polymer nanocomposites containing carbon nanotubes. Macromolecules 39, 5194-5205. doi: 10.1021/ma060733p

Moudjahed, M., Dermeche, L., Benadji, S., Mazari, T., and Rabia, C. (2016). Dawson-type polyoxometalates as green catalysts for adipic acid synthesis. $J$. Mol. Catal. A Chem. 414, 72-77. doi: 10.1016/j.molcata.2015.12.014

Mouheb, L., Dermeche, L., Mazari, T., Benadji, S., Essayem, N., and Rabia, C. (2018). Clean adipic acid synthesis from liquid-phase oxidation of cyclohexanone and cyclohexanol using (NH4)(x)A(y)PMo(12)O(40) (A: Sb, $\mathrm{Sn}, \mathrm{Bi}$ ) mixed heteropolysalts and hydrogen peroxide in free solvent. Catal. Lett. 148, 612-620. doi: 10.1007/s10562-017-2263-6

Nale, S. D., Rathod, P. V., and Jadhav, V. H. (2017). Manganese incorporated on glucose as an efficient catalyst for the synthesis of adipic acid using molecular $\mathrm{O}_{2}$ in aqueous medium. Appl. Catal. A 546, 122-125. doi: 10.1016/j.apcata.2017.08.008

Patra, A. K., Dutta, A., and Bhaumik, A. (2013). Mesoporous core-shell fenton nanocatalyst: a mild, operationally simple approach to the synthesis of adipic acid. Chem. Eur. J. 19, 12388-12395. doi: 10.1002/chem.201301498

Perkel, A. L., and Voronina, S. G. (2019). Liquid-phase oxidation of cyclohexane. Cyclohexyl hydroperoxide, cyclohexanol, and cyclohexanone, mechanisms of formation and transformation. Russ. Chem. Bull. 68, 480-492. doi: 10.1007/s11172-019-2443-1

Pisk, J., Agustin, D., and Poli, R. (2019). Organic salts and merrifield resin supported PM12O40 (3-) ( $\mathrm{M}=$ Mo or $\mathrm{W})$ as catalysts for adipic acid synthesis. Molecules 24:783. doi: 10.3390/molecules240 40783

Polen, T., Spelberg, M., and Bott, M. (2013). Toward biotechnological production of adipic acid and precursors from biorenewables. J. Biotechnol. 167, 75-84. doi: 10.1016/j.jbiotec.2012.07.008

Qadir, M. I., Scholten, J. D., and Dupont, J. (2014). $\mathrm{TiO}_{2}$ nanomaterials: highly active catalysts for the oxidation of hydrocarbons. J. Mol. Catal. A Chem. 383, 225-230. doi: 10.1016/j.molcata.2013.12.012

Rahman, A., Mupa, M., and Mahamadi, C. (2016). A mini review on new emerging trends for the synthesis of adipic acid from metal-nano heterogeneous catalysts. Catal. Lett. 146, 788-799. doi: 10.1007/s10562-015$1682-5$

Rathod, P. V., and Jadhav, V. H. (2018). Efficient method for synthesis of 2,5-furandicarboxylic acid from 5-hydroxymethylfurfural and fructose using $\mathrm{Pd} / \mathrm{CC}$ catalyst under aqueous conditions. ACS Sustain. Chem. Eng. 6, 5766-5771. doi: 10.1021/acssuschemeng.7b03124

Rezaei, M., Chermahini, A. N., and Dabbagh, H. A. (2017). Green and selective oxidation of cyclohexane over vanadium pyrophosphate supported on mesoporous KIT-6. Chem. Eng. J. 314, 515-525. doi: 10.1016/j.cej.2016.12.009

Ribeiro de Sousa Martins, L. M. D., Correia Carabineiro, S. A., Wang, J., Martins Rocha, B. G., Jose Maldonado-Hodar, F., and Latourrette de Oliveira Pombeiro, A. J. (2017). Supported gold nanoparticles as reusable catalysts for oxidation reactions of industrial significance. Chemcatchem 9, 1211-1221. doi: $10.1002 /$ cctc. 201601442 
Sato, K., Aoki, M., and Noyori, R. (1998). A “green” route to adipic acid: direct oxidation of cyclohexenes with 30 percent hydrogen peroxide. Science 281, 1646-1647. doi: 10.1126/science.281.5383.1646

Shen, J., Chen, H., Chen, K., Qin, Y., Lu, X., Ouyang, P., et al. (2018). Atomic layer deposition of a pt-skin catalyst for base-free aerobic oxidation of 5hydroxymethylfurfural to 2,5-furandicarboxylic acid. Ind. Eng. Chem. Res. 57, 2811-2818. doi: 10.1021/acs.iecr.7b05101

Shi, C., Zhu, B., Lin, M., Long, J., and Wang, R. (2011). Cyclohexane mild oxidation catalyzed by new titanosilicate with hollow structure. Catal. Today 175, 398-403. doi: 10.1016/j.cattod.2011.05.012

Shi, H., Thapa, P. S., Subramaniam, B., and Chaudhari, R. V. (2018). Oxidation of glucose using mono- and bimetallic catalysts under base-free conditions. Org. Process Res. Dev. 22, 1653-1662. doi: 10.1021/acs.oprd.8b00302

Shimizu, A., Tanaka, K., Ogawa, H., Matsuoka, Y., Fujimori, M., Nagamori, Y., et al. (2003). An industrial process for adipic acid production by the liquidphase oxidation of cyclohexanone with molecular oxygen. Bull. Chem. Soc. Jpn. 76, 1993-2001. doi: 10.1246/bcsj.76.1993

Shiraishi, Y., Shiota, S., Hirakawa, H., Tanaka, S., Ichikawa, S., and Hirai, T. (2017). Titanium dioxide/reduced graphene oxide hybrid photocatalysts for efficient and selective partial oxidation of cyclohexane. ACS Catal. 7, 293-300. doi: 10.1021/acscatal.6b02611

Skoog, E., Shin, J. H., Saez-Jimenez, V., Mapelli, V., and Olsson, L. (2018). Biobased adipic acid - the challenge of developing the production host. Biotechnol. Adv. 36, 2248-2263. doi: 10.1016/j.biotechadv.2018.10.012

Smith, T. N., Hash, K., Davey, C. L., Mills, H., Williams, H., and Kiely, D. E. (2012). Modifications in the nitric acid oxidation of D-glucose. Carbohydr. Res. 350, 6-13. doi: 10.1016/j.carres.2011.12.024

Solmi, S., Morreale, C., Ospitali, F., Agnoli, S., and Cavani, F. (2017). Oxidation of d-glucose to glucaric acid using Au/C catalysts. Chemcatchem 9, 2797-2806. doi: $10.1002 /$ cctc. 201700089

Tahar, A., Benadji, S., Mazari, T., Dermeche, L., Marchal-Roch, C., and Rabia, C. (2015). Preparation, characterization and reactivity of keggin type phosphomolybdates, $\mathrm{H}_{3-2 x} \mathrm{Ni}_{x} \mathrm{PMo}_{12} \mathrm{O}_{40}$ and $\left(\mathrm{NH}_{4}\right)_{3-2 x} \mathrm{Ni}_{\mathrm{x}} \mathrm{PMo}_{12} \mathrm{O}_{40}$, for adipic acid synthesis. Catal. Lett. 145, 569-575. doi: 10.1007/s10562-0141373-7

Tangestaninejad, S., Moghadam, M., Mirkhani, V., Mohammadpoor-Baltork, I., and Ghani, K. (2008). $\mathrm{MoO}_{2}(\mathrm{acac})_{2}$ supported on MCM-41: an efficient and reusable catalyst for alkene epoxidation with tert-BuOOH. J. Iran. Chem. Soc. 5, 71-79. doi: 10.1007/BF03246492

Tangestaninejad, S., Moghadam, M., Mirkhani, V., Mohammadpoor-Baltork, I., and Ghani, K. (2009). Alkene epoxidation catalyzed by molybdenum supported on functionalized MCM-41 containing N-S chelating schiff base ligand. Catal. Commun. 10, 853-858. doi: 10.1016/j.catcom.2008. 12.010

Unnarkat, A. P., Sridhar, T., Wang, H., Mahajani, S., and Suresh, A. K. (2016). Cobalt molybdenum oxide catalysts for selective oxidation of cyclohexane. Aiche J. 62, 4384-4402. doi: 10.1002/aic.15335

Vafaeezadeh, M., Hashemi, M. M., and Shakourian-Fard, M. (2012). Design of silica supported task-specific ionic liquid catalyst system for oxidation of cyclohexene to adipic acid with $30 \% \mathrm{H}_{2} \mathrm{O}_{2}$. Catal. Commun. 26, 54-57. doi: 10.1016/j.catcom.2012.04.031

Van de Vyver, S., and Roman-Leshkov, Y. (2013). Emerging catalytic processes for the production of adipic acid. Catal. Sci. Technol. 3, 1465-1479. doi: 10.1039/C3CY20728E

Vardon, D. R., Franden, M. A., Johnson, C. W., Karp, E. M., Guarnieri, M. T., Linger, J. G., et al. (2015). Adipic acid production from lignin. Energy Environ. Sci. 8, 617-628. doi: 10.1039/C4EE03230F

Ventura, M., Lobefaro, F., de Giglio, E., Distaso, M., Nocito, F., and Dibenedetto, A. (2018). Selective aerobic oxidation of 5-hydroxymethylfurfural to 2,5diformylfuran or 2-formyl-5-furancarboxylic acid in water by using $\mathrm{MgO}$ center dot $\mathrm{CeO}_{2}$ mixed oxides as catalysts. Chemsuschem 11, 1305-1315. doi: $10.1002 /$ cssc. 201800334

Wang, B., Zhang, Z., Zhang, X., Sun, S., Wu, L., and Xing, R. (2018). Efficient and convenient oxidation of cyclohexene to adipic acid with $\mathrm{H}_{2} \mathrm{O}_{2}$ catalyzed by $\mathrm{H}_{2} \mathrm{WO}_{4}$ in acidic ionic liquids. Chem. Pap. 72, 643-649. doi: 10.1007/s11696-017-0303-8

Wang, L., Chen, Z., Huang, M., Yang, Z., Sun, P., Wang, K., et al. (2016). A green route to cyclohexanone: selective oxidation of cyclohexanol promoted by non-precious catalyst of $\mathrm{h}-\mathrm{WO}_{3}$ nanorods. Catal. Lett. 146, 1283-1290. doi: 10.1007/s10562-016-1751-4

Wang, X., Zhang, X., He, X., Ma, A., Le, L., and Lin, S. (2015). Facile electrodeposition of flower-like $\mathrm{PMo}_{12}-\mathrm{Pt} / \mathrm{rGO}$ composite with enhanced electrocatalytic activity towards methanol oxidation. Catalysts 5, 1275-1288. doi: $10.3390 /$ catal5031275

Wei, L., Zhang, J., Deng, W., Xie, S., Zhang, Q., and Wang, Y. (2019). Catalytic transformation of 2,5-furandicarboxylic acid to adipic acid over niobic acid-supported Pt nanoparticles. Chem. Commun. 55, 8013-8016. doi: 10.1039/C9CC02877C

Wojcieszak, R., Cuccovia, I. M., Silva, M. A., and Rossi, L. M. (2016). Selective oxidation of glucose to glucuronic acid by cesium-promoted gold nanoparticle catalyst. J. Mol. Catal. A Chem. 422, 35-42. doi: 10.1016/j.molcata.2016. 02.008

Xia, C., Ju, L., Zhao, Y., Xu, H., Zhu, B., Gao, F., et al. (2015). Heterogeneous oxidation of cyclohexanone catalyzed by TS-1: combined experimental and DFT studies. Chinese J. Catal. 36, 845-854. doi: 10.1016/S1872-2067(15)60859-2

Xia, C., Zhao, Y., Zhu, B., Lin, M., Peng, X., Dai, Z., et al. (2018). Environmentally-friendly catalytic oxidation of cyclohexanone with $30 \%$ $\mathrm{H} 2 \mathrm{O} 2$ solution: a comparison study between hollow titanium silicate and dealuminated HBEA zeolites. China Pet. Process. Petrochem. Technol. 20, $8-19$.

Xiao, Z., Zhan, W., Guo, Y., Guo, Y., Gong, X., and Lu, G. (2016). The synthesis of Co-doped SAPO-5 molecular sieve and its performance in the oxidation of cyclohexane with molecular oxygen. Chinese J. Catal. 37, 273-280. doi: 10.1016/S1872-2067(15)61014-2

Yang, B., Leclercq, L., Schmitt, V., Pera-Titus, M., and Nardello-Rataj, V. (2019). Colloidal tectonics for tandem synergistic pickering interfacial catalysis: oxidative cleavage of cyclohexene oxide into adipic acid. Chem. Sci. 10, 501-507. doi: 10.1039/C8SC03345E

Yang, D., Wu, T., Chen, C., Guo, W., Liu, H., and Han, B. (2017). The highly selective aerobic oxidation of cyclohexane to cyclohexanone and cyclohexanol over $\mathrm{V}_{2} \mathrm{O}_{5} @ \mathrm{TiO}_{2}$ under simulated solar light irradiation. Green Chem. 19, 311-318. doi: 10.1039/C6GC 02748B

Yang, J., Lu, Y., Zhao, Y., Bai, Z., Ma, Z., and Deng, Y. (2019). Sitedirected mutation to improve the enzymatic activity of 5-carboxy2-pentenoyl-CoA reductase for enhancing adipic acid biosynthesis. Enzyme Microb. Technol. 125, 6-12. doi: 10.1016/j.enzmictec.2019. 02.006

Yang, X., Li, Y., Yu, H., Gui, X., Wang, H., Huang, H., et al. (2016). Enhanced catalytic activity of carbon nanotubes for the oxidation of cyclohexane by filling with $\mathrm{Fe}, \mathrm{Ni}$, and FeNi alloy Nanowires. Aust. J. Chem. 69, 689-695. doi: 10.1071/CH15516

Yu, H., Ru, S., Dai, G., Zhai, Y., Lin, H., Han, S., et al. (2017). An efficient Iron(III)-catalyzed aerobic oxidation of aldehydes in water for the green preparation of carboxylic acids. Angew. Chem. Int. Ed. 56, 3867-3871. doi: 10.1002/anie.201612225

Zhang, F., Yang, H., He, J., and Chen, D. (2013). Preparation of lanthanum modified solid catalyst $\mathrm{SnO} 2$ - WO3/La2O3 and its catalytic performance for synthesis of adipic acid. J. Chinese Rare Earth Soc. 34, 46-49. doi: 10.16533/j.cnki.15-1099/tf.2013.04.018

Zhang, J., Li, J., Tang, Y., Lin, L., and Long, M. (2015). Advances in catalytic production of bio-based polyester monomer 2,5-furandicarboxylic acid derived from lignocellulosic biomass. Carbohydr. Polym. 130, 420-428. doi: 10.1016/j.carbpol.2015.05.028

Zhang, S., Sun, X., Zheng, Z., and Zhang, L. (2018). Nanoscale center-hollowed hexagon $\mathrm{MnCo} 2 \mathrm{O} 4$ spinet catalyzed aerobic oxidation of 5-hydroxymethylfurfural to 2,5-furandicarboxylic acid. Catal. Commun. 113, 19-22. doi: 10.1016/j.catcom.2018. 05.004

Zhang, Z., and Deng, K. (2015). Recent advances in the catalytic synthesis of 2,5-furandicarboxylic acid and its derivatives. ACS Catal. 5, 6529-6544. doi: 10.1021/acscatal.5b01491

Zhang, Z., and Huber, G. W. (2018). Catalytic oxidation of carbohydrates into organic acids and furan chemicals. Chem. Soc. Rev. 47, 1351-1390. doi: 10.1039/C7CS00213K 
Zhao, R., Wang, Y. Q., Guo, Y. L., Guo, Y., Liu, X. H., Zhang, Z. G., et al. (2006). A novel Ce/AlPO-5 catalyst for solvent-free liquid phase oxidation of cyclohexane by oxygen. Green Chem. 8, 459-466. doi: 10.1039/b517656e

Zhou, J. D., Cao, F., Yu, Z. L., Wen, B. B., Cui, L. Y., Tang, Z. Q., et al. (2016). Research progress in preparation and application of bio-based 2,5furandicarboxylic acid as polyester monomer. Acta Polym. Sin. 1, 1-13. doi: 10.11777/jissn1000-3304.2016.15142

Zou, G., Zhong, W., Mao, L., Xu, Q., Xiao, J., Yin, D., et al. (2015a). A nonnitric acid method of adipic acid synthesis: organic solvent- and promoterfree oxidation of cyclohexanone with oxygen over hollow-structured Mn/TS-1 catalysts. Green Chem. 17, 1884-1892. doi: 10.1039/C4GC02333A

Zou, G., Zhong, W., Xu, Q., Xiao, J., Liu, C., Li, Y., et al. (2015b). Oxidation of cyclohexane to adipic acid catalyzed by Mn-doped titanosilicate with hollow structure. Catal. Commun. 58, 46-52. doi: 10.1016/j.catcom.2014.08.026
Conflict of Interest: XX was employed by the company Huabei Oil Field Company at PetroChina.

The remaining authors declare that the research was conducted in the absence of any commercial or financial relationships that could be construed as a potential conflict of interest.

Copyright (c) 2020 Yan, Zhang, Wang, Liu, Sun, Zhou, Zhang, Zhang, Xu, Shen and Jin. This is an open-access article distributed under the terms of the Creative Commons Attribution License (CC BY). The use, distribution or reproduction in other forums is permitted, provided the original author(s) and the copyright owner(s) are credited and that the original publication in this journal is cited, in accordance with accepted academic practice. No use, distribution or reproduction is permitted which does not comply with these terms. 